\title{
A democratização da escola pública: velhos e novos modelos de gestão escolar
}

The democratization of public school: old and new school management models

\author{
Maria José Ferreira Ruiz* \\ Universidade Estadual de Londrina
}

Edwylson de Lima Marinheiro**

Universidade Estadual de Londrina

Resumo O objetivo do texto é discutir as alterações nos modelos de gestão pública e as implicações para a gestão educacional. Partimos do pressuposto que o padrão de gestão das instituições públicas se altera conforme a reestruturação do capitalismo e suas crises constantes. $\mathrm{O}$ estudo faz referência a três modelos de gestão, sendo estes: a gestão burocrática, a gestão democrática e a gestão empresarial gerencial. Conclui que na gestão pública há a predominância dos modelos de gestão empresarial gerencial e da gestão burocrática, que ainda não foi superada. Contudo, contraditoriamente, a gestão democrática está presente na legislação da educação, por conta da luta dos trabalhadores desta área, mas se desenrola de forma muito tênue e embrionária nas escolas públicas.

PALAVRAS-CHAVE: Democratização da escola pública; Modernização do estado; Gestão educacional.

Abstract The objective of this paper is to discuss the changes in the public management models and the implications for educational management. We assumed that the standard of management of public institutions changes as the restructuring of capitalism and its constant crises. The study makes reference to three management models, namely: bureaucratic management, democratic management and the business management. It is concluded that in public administration there is a predominance of model management business and bureaucratic management, which has not yet been surpass. However, contradictorily, the democratic management is present in the educational legislation, due to the struggle of workers in this area, but unfolds very thin and embryonic in public schools.

KEYWORDS: Democratization of public school; State modernization; Educational management. 


\section{Introdução}

O texto faz uma discussão bibliográfica que dá sustentação à pesquisa ${ }^{1}$ de maior amplitude que discute as políticas e programas governamentais, que visam democratizar a escola de Educação Básica. O estudo está vinculado ao Grupo de Pesquisa "Estado, Políticas Públicas e Gestão da Educação". Nos estudos deste grupo, entendemos por democratização da educação a ampliação da inclusão, do acesso e da permanência de todos em uma educação escolar de qualidade. A democratização também se refere às formas de organização escolar que permitam a participação da comunidade interna e externa nos processos de tomada de decisões sobre aquilo que diz respeito à gestão da escola pública.

Neste texto, temos o objetivo de discutir as alterações nos modelos de gestão pública e as implicações destas alterações para a gestão educacional. Partimos do pressuposto que não há um único modelo de gestão escolar, mas que vários padrões se desenvolvem ao mesmo tempo, contudo, há a predominância de alguns sobre outros.

Os estudos do grupo têm como princípio que a gestão escolar não é algo a ser analisado de forma abstrata, porquanto, ela se desenvolve a partir do modo de produção que vige na sociedade em que a escola está inserida. Em outras palavras, não é possível que se idealize um modelo de gestão, abstratamente, e busque aplicá-lo nas instituições públicas. $\mathrm{O}$ modelo que a gestão escolar assume tem por base a atividade material e real desenvolvida pelos sujeitos sociais que atuam na sociedade como um todo. Atualmente, a sociedade organiza-se a partir do modo de produção capitalista. Nas palavras de Rosar,

A atual realidade educacional brasileira resulta da evolução econômica, política e social do país, no sentido das mudanças que ocorrem na sua estrutura econômica, desencadeando transformações no regime político e na estrutura social brasileira nos diferentes momentos da sua história. Para compreender essa realidade é necessário explicitar os condicionantes econômicos, políticos e sociais que engendram a sociedade brasileira. (ROSAR, 2012, p. 7).

Assim, para entender a realidade educacional é necessário observar que o capitalismo, desde sua origem, vive constantes crises estruturais. A fim de manter a hegemonia deste sistema, a classe dominante faz um esforço em difundir a ideia de que não é o capitalismo que está em crise, mas sim as instituições sociais. Desta forma, atribui a crise ao Estado, à escola pública e à gestão das instituições públicas e advoga que reformas nestas e em outras áreas são necessárias. Estas reformas apontam para novos padrões de gestão do Estado e, consequentemente, para novos padrões de gestão dos serviços públicos.

Tendo isso em vista, na primeira seção, apresentamos elementos da crise do sistema econômico atual e a ascensão do neoliberalismo no Brasil. $\mathrm{Na}$ sequência, discutimos que o neoliberalismo dá as bases para a reforma do Estado, que enaltece as parcerias público-privadas em todas as áreas, dentre elas a educação. Finalizamos o texto, na última seção, apresentando ao leitor os paradigmas de gestão escolar que se mesclam nas escolas públicas, nos dias atuais, influenciados pelas questões mais amplas do contexto econômico e político da sociedade de classes. 


\section{Crises do capital}

As crises econômicas e sociais eclodem pelo mundo afora e isso não é novidade. Basta acompanhar as manifestações e as ações sociais que emergem diuturnamente em forma de protestos, ora mais pacíficos e outras vezes mais violentos, para perceber que algo não vai bem. Gentili (2005) aponta que a crise precisa ser analisada sempre de uma forma global. Desta forma, não é possível falar em crises setoriais, como a crise na gestão do Estado, ou a crise na escola pública, perdendo de vista o contexto mais amplo, no qual as mesmas estão inseridas.

Wallerstein (2001) é referência para o entendimento das crises contemporâneas. Em meados da década de 1980, esse autor apresentou uma análise das crises do sistema capitalista. No livro "O capitalismo histórico e a civilização capitalista", o autor defendeu que o capitalismo trouxe, de fato, desenvolvimento tecnológico e científico e através deste desenvolvimento muito se avançou em diferentes áreas. Entretanto, este desenvolvimento não se sustenta, diante da má distribuição da riqueza em nível mundial, diante da depredação ambiental e do fato de que a grande maioria da população não usufrui das benesses de forma igualitária.

Com esses argumentos, Wallerstein (2001) aponta que há uma tendência bastante provável de que o sistema atual não se sustente ainda por muito tempo. Portanto, a crise do final do século XX, que se arrasta na segunda década do século atual, seria a derradeira crise do sistema. Wallerstein (2001) indica que à medida que o capitalismo prossegue em seu rumo histórico vai tornando cada vez pior e não melhor, como proclamam os defensores do sistema. Prossegue dizendo que é pouco evidente que no mundo atual exista mais liberdade, igualdade e fraternidade do que anos atrás. Em verdade, o que ocorre é o oposto. Mesmo entendendo que os mundos anteriores ao capitalismo fossem de fato mundos de pouca liberdade, pouca igualdade e pouca fraternidade, a questão é que no capitalismo estes princípios regrediram de forma incomparável. Desta feita, o capitalismo representou mais regresso do que progresso nas questões de ordem social, trabalhistas e ambientais, dentre outras.

Wallerstein (2001) lembra que não se pode esquecer que os sistemas são históricos. Portanto, aparecem e, ocasionalmente, desaparecem, em decorrência de processos internos e bastante específicos, que conduzem a contradições internas, tais que desembocam em crises estruturais. As crises não são momentâneas e levam tempo para se manifestarem. $\mathrm{O}$ atual sistema entrou em sua crise estrutural no começo do século XX e, muito provavelmente, assistirá ao seu fim, como sistema histórico, no século atual. O sistema que sucederá a esse é ainda difícil de prever. O que se pode fazer, de fato, é analisar as extensões da atual crise estrutural, e tentar especular sobre as direções para as quais a crise sistêmica conduz a humanidade.

Para Wallerstein (2001), isso aponta para uma nova ordem mundial que será construída muito devagar, em modalidades que são difíceis de imaginar e predizer. Este teórico é otimista ao antever que é possível que após muitas convulsões sociais, que acontecerão em maior ou em menor escala em diferentes países, há a possibilidade de que a ordem mundial que virá após a atual seja boa, ou senão, menos perversa. 
Mészáros (2009), na tentativa de entender a crise sistêmica contemporânea, também tem desenvolvido reflexões críticas sobre o capitalismo, sua lógica, a forma que se apresenta e as engrenagens e mecanismos através dos quais funciona. Para ele, o capitalismo é um sistema abrangente e muito poderoso. Organiza-se à volta de um núcleo formado pelo tripé capital, trabalho e Estado. Este sistema, na concepção do autor, não tem limites para sua expansão, o que o torna incontrolável e destrutivo em sua essência.

O capitalismo aumenta, de forma inestimável, a competitividade e a concorrência intercapitais, levando a consequências das mais nefastas imagináveis. Mészáros (2009) destaca duas dessas consequências como sendo as mais graves, sendo essas a precarização da força humana que trabalha e a degradação inestimável do meio ambiente. Para produzir mercadoria, o capitalismo utiliza-se do trabalho do homem e da tecnologia, destruindo a natureza de forma nunca anteriormente vista, de forma predatória, colocando em risco a vida no planeta.

Como não poderia deixar de ser, a fim de se expandir cada vez mais e mais, o capitalismo provoca uma crise endêmica, crônica e permanente, que leva a visualizar a destruição global da humanidade. Essa crise, para Mészáros (2009), não é possível de ser resolvida dentro da própria lógica do capitalismo. Não serão as reformas superficiais, paliativas e pontuais que darão conta de reverter o quadro catastrófico pelo qual caminha a humanidade. $O$ autor defende que a única forma de evitar a destruição é colocar em pauta a atualidade histórica da alternativa socialista, indo para além da lógica do capital.

Mészáros (2009) enfatiza que a lógica do capitalismo tem sua estrutura e seu sistema de controle no âmbito extraparlamentar. Desta feita, qualquer tentativa de superação do sistema não pode se restringir apenas a esfera institucional. Para ele, só um vasto movimento de massas radical, que vá além do parlamentar, pode ser capaz de destruir o sistema, assim como o domínio social do capitalismo. Mesmo porque o Estado moderno, da forma que se apresenta, é entendido pelo autor como uma estrutura a mando do próprio capitalismo, sendo o Estado um pré-requisito para o próprio sistema ser viável e para que continue em sua reprodução. Assim, defende que não é possível conceber o Estado moderno sem o capitalismo, assim como não é possível conceber o capitalismo sem o Estado moderno.

Para Mészáros (2005), as reformas propostas neste início de século tratam de alguns ajustes e reparos menores. No livro "Educação para além do capital", este autor discute a reforma da educação. Propõe, então, um debate a fim de ajudar a desvelar os reais motivos e interesses que ficam obscuros diante de tantas reformas. Esse autor atenta para o fato de que essas propostas reformistas são pensadas

[...] apenas com o único e legítimo objetivo de corrigir algum detalhe defeituoso da ordem estabelecida, de forma que sejam mantidas intactas as determinações estruturais fundamentais da sociedade como um todo, em conformidade com as exigências inalteráveis da lógica global de um determinado sistema de reprodução. (MÉSZÁROS, 2005, p. 25). 
Portanto, as reformas trazem pouco ou nenhum ganho aos trabalhadores. Por outro lado, acabam por favorecer a lógica da imutabilidade do sistema, favorecendo muito mais a classe dominante. Mesmo entendendo essa questão e concordando com ela, a seguir buscaremos ilustrar alguns elementos da reforma do Estado brasileiro, uma vez que é necessário entendê-la para compreender a reforma no padrão de gestão da educação.

\section{A modernização do Estado e as parcerias público-privadas}

O Estado passa por um processo de modernização e reformas para adequálo à reestruturação produtiva do modo de produção capitalista (capitalismo financeiro). A reforma do Estado é um fenômeno que teve seu marco na década de 1970, nos EUA e na Inglaterra, tendo em vista a crise financeira por qual passa estes países, neste período, e, também, a necessidade de por em prática o programa neoliberal de ajustes ficais (ANDERSON, 1995). Na década de 1980, a crise econômica nos países centrais refletiu nos países em desenvolvimento. Ocorreu uma completa desorganização monetário-financeira nos países periféricos, que necessitaram de empréstimos externos, para dinamizar e garantir o desempenho de suas economias.

O Banco Mundial (BM), um dos maiores concessores de créditos para esses países, introduziu novas modalidades de empréstimos e de ajustes estruturais. Em contrapartida, exigiu algumas condições para que os países conseguissem os empréstimos, sendo uma delas o redimensionamento do papel do Estado na economia de mercado, a fim de que esta instituição atendesse ao máximo o setor produtivo da economia. A reforma do Estado foi estimulada pelos organismos internacionais, com a justificativa que para que houvesse maior e melhor desenvolvimento econômico seria preciso que os Estados se abrissem para o comércio exterior e buscassem equilibrar os orçamentos e a estabilidade interna da moeda. Para isso, seria necessário o ajuste fiscal, cortes nos orçamentos e parcerias financeiras entre o Estado e os setores privados da economia.

O Estado de bem-estar social sofreu pressões do Banco Mundial. Foi visto como um Estado burocrático, ineficiente, centralizador, que trazia para si toda responsabilidade com os serviços sociais e não estabelecia parcerias com a iniciativa privada, sendo este fato um entrave para a economia de mercado.

Nesta perspectiva, tentou-se deslocar, ideologicamente, o foco da crise. Não seria o sistema econômico e suas contradições e antagonismos que estavam a provocar crises constantes, mas sim o Estado burocrático. A ideia era educar para um consenso sobre a necessidade de encontrar formas de recompor as condições de acumulação do capital. Neste contexto, em meados da década de 1990, Bresser Pereira apontou o modelo de Estado social-liberal como capaz de assumir o papel de estimulador para preparar as empresas e o país para a competição generalizada (SILVA, 2003).

O Estado social-liberal não se assemelha nem ao Estado social-burocrático (bem estar), responsável pela contratação direta de professores e outros trabalhadores para realizar de forma monopolista os serviços sociais, contudo, também não é um Estado neoliberal, uma vez que este último renuncia as suas responsabilidades sociais 
(PEREIRA, apud SILVA, 2003). Este novo modelo de Estado protege os direitos sociais ao financiar as organizações públicas não-estatais, que prestam serviços de educação, saúde, cultura, assistência social e, para os reformadores, são mais eficientes ao introduzirem a competição e a flexibilidade da provisão desses serviços (SILVA, 2003, MELO; FALLEIROS, 2005).

Desta forma, conforme Melo e Falleiros (2005), utiliza-se terminologias (quase-mercado, público não estatal, etc) capazes de confundir e educar para um perigoso consenso que obscurece a compreensão sobre os diferentes projetos de sociedade em disputa no mundo atual. O Estado, em favor do princípio da eficiência, deve aperfeiçoar o uso dos recursos públicos, a fim de obter melhores resultados, estabelecendo parcerias com outros setores. A partir da reforma da aparelhagem estatal, baseada em três eixos (privatização, publicização e terceirização), o governo redefine as suas áreas de atuação, distinguindo aquelas atividades que são de exclusiva responsabilidade do Estado e aquelas que podem ser executadas através de parcerias. A educação e a saúde "são atividade competitivas, que podem ser controladas não apenas através da administração pública gerencial, mas também e principalmente através do controle social e da constituição de quase-mercado" (PEREIRA, 1997, p. 25).

Assim, sob a alcunha de quase-mercado, opera-se uma construção ideológica que mascara a expansão do capital em áreas que são essencialmente públicas, como a área da saúde e da educação. Isso ameaça o caráter universalista destes direitos sociais inalienáveis (saúde e educação) e a solidariedade, presentes nas políticas sociais do Estado, providência e ainda provoca mudanças nos valores sociais e, consequentemente, na concepção de justiça social. Os cidadãos vão assim deixando de partilhar de direitos iguais e universais, passando a se valorizar o mérito e a disponibilidade financeira que determinam o direito de ter acesso aos bens de consumo coletivo (MELO; FALLEIROS, 2005).

É importante destacar que o governo brasileiro atual não rompe com o projeto de modernização do Estado, pois continua a estabelecer alianças políticas, consensos e ajustes ao capital financeiro globalizado. Este governo não se julga adepto ao projeto social-liberal, mas não consegue se libertar de seus escopos. Enquanto isso, o prenúncio ideológico do neoliberalismo, mesmo que com outras roupagens e algumas modernizaçôes (terceira via, etc), segue seu curso e aprofunda-se (MELO; FALLEIROS, 2005).

Os representantes das oligarquias financeiras, os organismos internacionais (Banco Mundial, Organização Mundial do Comércio, Fundo Monetário Internacional), continuam solicitando a implementação das políticas neoliberais que, nas suas concepções, não colocam em risco o projeto de sociabilidade econômica do capital. Contudo, como este ideário não pode ser imposto, há que se fomentar a participação social, as consultas populares, a preparação das subjetividades. Enaltece-se, assim, a necessidade de educar o cidadão ativo que desenvolva uma consciência política capaz de se responsabilizar localmente pelos problemas sociais que, como procuramos demonstrar, não são locais, mais sim conjunturais, pois estão enraizados em uma crise estrutural de um modo de produção cambaleante e falido, dado a sua incapacidade de 
redistribuir as riquezas que produz. Neste contexto conturbado, as instituições públicas são chamadas a desenvolver projetos de gestão mais eficientes e eficazes. É sobre as questões específicas da gestão escolar que nos voltamos na sequência do texto.

\section{Velhos e novos modelos de gestão escolar}

A gestão escolar é um processo que ocorre entre interesses antagônicos das classes sociais e as crises do sistema capitalista. Entendemos que não há um único padrão de gestão escolar e sim uma mescla de modelos. Em nossos estudos, fazemos referência a três modelos de gestão, sendo estes: a gestão burocrática, a gestão democrática e a gestão empresarial gerencial. Estes padrões de gestão escolar estão diretamente relacionados ao desenvolvimento histórico da sociedade de classes e um ou outro fica em maior destaque em determinados momentos históricos.

No Brasil, durante o período ditatorial (1964-1985), podemos identificar por meio dos estudos da gestão escolar que vigorou o padrão da gestão burocrática. Para Tragtenberg (2005), em instituições organizadas pela lógica burocrática os trabalhadores não controlam a gestão dos insumos destinados à coletividade. As relações de trabalho são instituídas por uma sucessão de níveis hierárquicos que impedem a participação da base no planejamento e na tomada de decisões, sobre os assuntos que fazem parte do cotidiano das instituições.

No período ditatorial, houve uma forte incidência do ideário norte-americano na educação brasileira. Por meio dos acordos entre o Ministério da Educação (MEC) e a United States Agency for International Development (USAID), muitos professores eram enviados aos EUA para se apropriarem das formas de organização do trabalho no capitalismo. Retornavam ao Brasil para difundir as técnicas de controle pleno e absoluto do trabalho, sobre a força de trabalho dos professores. Isso se estendia desde o planejamento do processo de produção até as operações e atividades realizadas pelos trabalhadores, nas suas atividades cotidianas. Havia um esforço de organizar a produção de forma científica, pautada nos estudos da administração científica de Taylor.

Este esforço materializava-se na divisão técnica do trabalho. Nesta perspectiva, é a direção e a supervisão escolar que decidem sobre o processo produtivo nas escolas, a fim de garantir a apreensão de resultados otimizados da força de trabalho. A organização do trabalho administrativo e pedagógico das escolas, pautadas na burocracia, se dá por meio de uma estrutura hierárquica de poder que mantém a separação entre o pensar e o fazer, entre o trabalho intelectual e manual, num processo constante de organização da produção que intensifica as forças do capital sobre o trabalho.

No Brasil, no final da década de 1970 e em meados da década de 1980, iniciava-se um processo de abertura política, que vislumbrava o fim da ditadura militar. A administração pública burocrática passou a ser criticada por sua rigidez e ineficiência e por não buscar inovações que fossem adequadas ao desenvolvimento científico e tecnológico. Os trabalhadores, de forma geral, e os trabalhadores da educação, de forma específica, agregados em sindicatos e outras organizações afins, também se colocavam 
contrários à burocracia e à hierarquia nas instituições públicas e almejavam uma participação mais democrática e a descentralização do poder.

Sobre isso, Ruiz (2014) aponta que diferentes formas de organização dos trabalhadores, historicamente, lutaram e lutam pela educação pública. A autora verificou que a luta dos professores - da educação básica e do ensino superior - foi importante no processo de discussão e elaboração das políticas educacionais que contribuíram para ampliar o direito à educação pública, ao menos formalmente. Desta feita, a Constituição Federal de 1988, a Lei de Diretrizes e Bases da Educação Nacional (LDBEN 9394/96) e o Plano Nacional de Educação (2001-2010) asseguram a educação como direito de todo cidadão e dever do Estado e inserem o princípio da gestão democrática.

No entanto, anterior à inserção da gestão democrática na legislação houve ampla mobilização dos trabalhadores da educação, na década de 1980. Nesta perspectiva, o Fórum Nacional em Defesa da Escola Pública (FNDEP) foi um espaço expressivo no cenário nacional. A princípio, a luta do Fórum foi pela defesa da escola pública e gratuita e pela necessidade de garantir que os recursos públicos fossem destinados única e exclusivamente para a escola pública. A seguir, começou a aparecer na pauta de discussões desse Fórum a necessidade de lutar pela gestão democrática das instituições de ensino público.

A gestão democrática, fruto da luta dos trabalhadores da educação, pressupõe a participação de toda comunidade na organização do trabalho pedagógico, na elaboração do projeto político-pedagógico, na organização e participação de Conselhos Escolares e nos processos de decisão coletiva, no interior das instituições escolares. Uma participação sócio-política que vai do planejamento, passa pela execução das atividades e desemboca na avaliação de todo o processo.

Importante destacar que se o processo de luta política dos trabalhadores trouxe avanços em relação à conquista da democratização da educação, esse processo ocorre quase concomitantemente ao avanço do neoliberalismo que se alastra no país, na década seguinte. É nesta década que a gestão empresarial gerencial toma forma e invade as instituições públicas. Este modelo de gestão advém de um amplo processo de modernização da gestão do aparato estatal, difundida nos marcos da década de 1990, mais especificamente a partir de 1995, com a reforma do Estado brasileiro. Este processo impacta na formulação de novas propostas de gestão. O setor empresarial, visto como mais moderno, eficiente e eficaz, passa a ser o novo modelo para a gestão da coisa pública.

Como explicitam Araújo e Castro (2011),

[...] no campo da educação, o modelo de gestão gerencial, pautado na descentralização administrativa do macro e micro-sistemas, se apresenta como fórmula prática para resolver os problemas crônicos da educação pública da América Latina. Esse modelo de gestão passa a ser incluído na agenda política como proposta inovadora e modernizadora da gestão educativa dos governos latino-americanos para garantia do sucesso escolar, tendo influência direta nos projetos políticos dos governos da região. (ARAÚJO; CASTRO, 2011, p. 90). 
Este modelo de gestão é difundido em grandes eventos que marcam a área da educação e ocorrem logo após o Consenso de Washington (1989), que teve como meta inserir os países periféricos na economia de mercado e erradicar a pobreza, sendo a educação uma importante área para atingir este escopo. Contudo, o interesse é econômico e não humanitário. Assim, durante a década de 1990 a 2000, estes eventos tiveram como pauta a negociação de um novo modelo de gestão que superasse a baixa qualidade da educação pública.

Em 1990, ocorre a Conferência Mundial de Educação para Todos, em Jontiem, na Tailândia. Esta conferência é um marco na formulação das políticas e programas governamentais para a educação. A partir desta Conferência, são instituídas várias estratégias a fim de otimizar a economia dos mercados dos países da América Latina e do Caribe (OLIVEIRA, 2000). Nos documentos produzidos a partir desta Conferência, identifica-se, claramente, a proposta de educação e de gestão escolar que é defendida, qual seja: otimizar a força de trabalho e aumentar a produtividade, enfatizando os aspectos econômicos, com uma visão mercadológica e com foco nos resultados.

Araújo e Castro (2011) apontam que, no ano de 2000, reúne-se, em Dakar - Senegal, a Cúpula Mundial de Educação. Neste evento, foram feitas avaliações sobre os desdobramentos das ações propostas na Conferência Mundial de Educação para Todos (1990). Na ocasião, conclui-se que os 155 países signatários da Conferência não haviam cumprido a meta de democratizar a educação, dado que ainda existia um número significativo de crianças e jovens sem acesso a educação.

Nas discussões e encaminhamentos, um dos focos foi colocado na questão da gestão educacional. Seria necessário ampliar a participação da sociedade na gestão educacional, num processo capaz de aumentar a prestação de contas, implementando o monitoramento sobre as estratégias de gestão. "A gestão educacional nessa perspectiva, deve ser realizada por meio do planejamento estratégico o qual surge como fórmula para racionalizar os parcos recursos financeiros, à imagem e à semelhança da empresa privada" (ARAÚJO; CASTRO, 2011, p. 101-102).

Os países signatários da Cúpula Mundial de Educação assumem a obrigação de desenvolver o modelo de gestão empresarial gerencial na educação. Esse modelo está sendo paulatinamente adotado nos países latino-americanos (ARAÚJO; CASTRO, 2011). A modernização da gestão sugere a adoção do gerencialismo no setor público, a fim de racionalizar o gasto com os serviços sociais. $O$ gerencialismo pode ser verificado na reorientação das práticas de gestão que se desenvolvem nas escolas,

$$
\begin{aligned}
& \text { [...] disseminando princípios orientados pela eficiência financeira } \\
& \text { [...]. Nesse caso os diretores tornam-se agentes hierárquicos tanto } \\
& \text { no controle quanto da implementação de mudança e são elemen- } \\
& \text { tos cruciais a serem responsabilizados pela prestação de contas e } \\
& \text { pelos resultados. (HOYLE; JOHN, 1995, apud, SHIROMA, 2004, } \\
& \text { p.120). }
\end{aligned}
$$

Nesta perspectiva, que é bem próxima da gestão burocrática, aparentemente, há uma tendência à meritocracia, ou seja, jogar para os indivíduos o mérito pelo sucesso, mas, também e, sobretudo, pelo fracasso da escola, sem levar em consideração as questões macro estruturais do sistema econômico e político. 
A meritocracia está intimamente relacionada à responsabilização (accountability) dos sujeitos pelos resultados da gestão escolar. O que é valorizado não é a ação/ comportamento em si, mas sim o resultado da ação/comportamento, conhecido como performance. As políticas de accountability são bastante valorizadas em países de neoliberalismo avançado, como no caso dos EUA.

Outro fator importante a se destacar nesta discussão - que impacta a política educacional de grande parte dos países, não só a do Brasil - é o papel que as avaliações assumem, no contexto da gestão empresarial gerencial. Nesta forma de gestão, as avaliações são vinculadas aos interesses oficiais do Estado avaliador, que intervém como instituição reguladora, a fim de manter vigilância sob os resultados e produtos obtidos no processo educativo. Dessa forma, a avaliação, tanto da aprendizagem como a institucional, ou em larga escala, passa a ser voltada para a prestação de contas dos resultados, que são de responsabilidade (accountability) de grupos isolados, não se levando em conta o contexto político e econômico de cada escola e/ou de cada sistema municipal de educação.

Há uma pressão muito grande advinda dos escalões superiores (MEC/ $\mathrm{SEB})$ sob os gestores municipais e escolares, para que estes apresentem resultados educacionais satisfatórios, que contribuam para alavancar os índices educacionais, capazes de reposicionar os países no ranking educacional, em avalições de larga escala, a exemplo do Programme for International Student Assessment (PISA). Estes índices são importantes para que os governos dos países prestem contas aos investidores (organismos internacionais) sobre os resultados obtidos, a partir dos investimentos dos recursos financeiros, que são impetrados em empréstimos concedidos aos países. Isso revela o caráter economicista e o poder regulador do Estado avaliador sob a educação em nível nacional e internacional (DIAS SOBRINHO, 2003).

Assim, a influência dos organismos internacionais na educação de grande parte dos países ocidentais tem conduzido a um processo nominado por alguns autores, como Akkari (2011), de "internacionalização das políticas educacionais". Diante desse fenômeno, os modelos educacionais são cada vez mais uniformes e padronizados, a gestão da educação e os diferentes programas e projetos educacionais se internacionalizam e os países são comparados e classificados a partir dos desempenhos que conseguem comprovar com os índices das avaliações internacionais, aos quais todos são submetidos. As exigências destes organismos (BM, OCDE, FMI, Unesco) seguem no sentido de uma tendência internacional de favorecer e estimular a cooperação econômica entre países. Alguns Estados, como São Paulo, chegam a contratar empresas internacionais para auxiliar na elaboração das políticas para a educação. Esse fenômeno é destacado por Freitas (2012) da seguinte forma:

Em nosso meio, o exemplo mais esclarecedor da maneira como estas ideias atingem o sistema público de ensino, entregando seu destino à iniciativa privada, pode ser encontrado no estado de São Paulo, em documento publicado pela Ação Educativa (2012). Um conjunto de entidades e fundações privadas está financiando a empresa de consultoria McKinsey para que formule a política educacional do estado. Não é diferente nos Estados Unidos, onde meia dúzia de fundações define a agenda educacional do país. (RAVITCH, apud, FREITAS, 2012, p. 396). 
Contudo, várias pesquisas e autores de diferentes países e estados vêm fazendo críticas ao efeito perverso desta internacionalização das políticas educacionais que, pautadas no neoliberalismo, enaltecem a responsabilização por resultados, que, dentre outros fatores, têm conduzido à política de bonificação ou de exposição pública dos fracassos. Para Freitas:

As políticas de responsabilização pressionam os professores a obter desempenho sempre crescente de seus alunos (Congresso dos Estados Unidos, 2002). Para tal, associam o desempenho do aluno ao próprio pagamento dos professores. Premidos pela necessidade de assegurar um salário variável na forma de bônus, os professores pressionam seus alunos, aumentando a tensão entre estes [...]. (NICHOLS; BERLINER, apud, FREITAS, 2012, p. 391).

As políticas de meritocracia e responsabilização (accountability) já estão em franco processo de implementação em alguns Estados brasileiros, dentre eles São Paulo, Minas Gerais e Pernambuco. A tendência é que essas políticas se alastrem por todo o Brasil, a depender do jogo de forças políticas que venham a se estabelecer no interior de cada um destes Estados.

Desta forma, segundo Ramos e Fernandes (2010), a concepção de gestão democrática vai sendo absorvida pelos conservadores e tendo seu significado distorcido e descaracterizado, se afastando significativamente daquela forma de gestão que foi mote de luta dos trabalhadores da educação. Esse processo vem minando a possibilidade de participação política do trabalhador na elaboração das políticas para a educação e no interior da escola, e concretiza a participação para a auto sustentação. Esta forma atual que a gestão escolar vai assumindo impulsiona a comunidade escolar a estabelecer uma relação de parceria com a sociedade, com o empresariado e com o Estado (Todos pela Educação), porém, descaracteriza o papel do Estado, enquanto provedor dos recursos da educação, mantendo-o no papel de fiscalizador e avaliador.

Assim, o Estado não perde o controle da política educacional, pelo contrário, continua indicando as diretrizes para a educação e controlando as avaliações em larga escala. Assim, a participação da comunidade na escola segue um modelo já amplamente difundido nas escolas dos EUA e de alguns países da Europa (APPLE, 2005; LAVAL, 2004), países estes ícones do neoliberalismo. A comunidade, ao invés de se unir com a escola no sentido de lutar para que os recursos e insumos públicos sejam satisfatórios para que possa desenvolver um processo de ensino e de aprendizagem de qualidade, que garanta o acesso ao conhecimento científico, passa a ter uma participação do cliente fiscalizador/consumidor.

\section{Apontamentos finais}

Nossos estudos, ainda em curso, carecem de comprovação empírica para as questões por ora postas neste texto apenas para reflexão e debate. A contribuição do texto segue no sentido de chamar a atenção para que a gestão escolar não seja discutida sem se levar em consideração os processos mais amplos das crises e reformas políticas e econômicas. A partir desta premissa, temos identificado que o modelo de gestão mais proeminente na atualidade tende a ser uma mescla do modelo empresarial 
gerencial e do modelo burocrático, que ainda não foi superado. Esses modelos são os que mais se adequam à perspectiva economicista que vem assolando a área da educação, tendo em vista a interferência dos organismos internacionais, que conduz a um processo de padronização das políticas para a educação.

Embora, contraditoriamente, na legislação educacional brasileira esteja ressalvada a gestão democrática, há um processo em curso por meio do qual as instituições públicas vão incorporando práticas e aspectos da cultura empresarial, competitiva e empreendedora, que nada ou pouco tem de democrática.

No Paraná, por exemplo, enquanto este artigo é redigido, há um processo de luta em curso que envolve os trabalhadores da educação de todo o Estado, no sentido de manterem os direitos trabalhistas e previdenciários conquistados. $\mathrm{O}$ governo atual, Beto Richa (PSDB), no final do mês de abril, utilizou de todo aparato repressivo do Estado e da polícia militar (bombas de gás lacrimogênio, cachorros, balas de borracha e spray de pimenta) para conter as manifestações legítimas de professores, estudantes e demais trabalhadores das escolas de educação básica e das universidades públicas paranaenses. Isso enquanto o direito à gestão democrática está garantido na Constituição Federal de 1988, na Lei de Diretrizes e Bases da Educação Nacional (Lei 9394/96) e no Plano Nacional de Educação (Lei 13005/2014). São as contradições que envolvem a gestão da educação na sociedade de classes.

Estudos realizados em outros países, a exemplo de Portugal (LIMA, 2012), trabalham também com a tese da hiperburocratização da gestão, embasada no uso das novas Tecnologias de Informação e Comunicação (TIC). Nesta perspectiva, parte dos processos burocráticos passa a ser realizada por sistemas integrados dos Ministérios da Educação que acirram, ainda mais, o controle sobre as escolas e professores.

Entretanto, não há dúvida que haja experiências de contradições e resistências, no sentido de lutar para que os sistemas educativos e a escola pública desenvolvam uma forma de organização mais democrática, pois, os trabalhadores não são sujeitos passivos e muitos vêm se organizando e atuando na contra corrente da internacionalização das políticas neoliberais na área da educação. Contudo, essas aspirações talvez só possam se concretizar após a organização de outro sistema de produção mais democrático e menos excludente.

\section{Referências}

AKKARI, A. Internacionalização das políticas educacionais: transformações e desafios. Petrópolis: Vozes, 2011, 143p.

ANDERSON, P. Balanço do neoliberalismo. In: SADER, E.; PABLO, G. (Orgs.). Pós-neoliberalismo: as políticas sociais e o Estado democrático. Rio de Janeiro: Paz e Terra, 1995, p. 9-23.

APPLE, M. W. Para além da lógica do mercado: compreendendo e opondo-se ao neoliberalismo. Rio de Janeiro: DP\&A, 2005.

ARAÚJO, S. de.; CASTRO, A. M. D. A. Gestão educativa gerencial: superação do modelo burocrático? Revista Ensaio: Avaliação e Políticas Públicas em Educação, Rio de Janeiro, v. 19, n. 70, p. 81-106, jan./mar. 2011. 
BRASIL. Constituição (1988). Constituição da República Federativa do Brasil: promulgada em 5 de outubro de 1988. Disponível em: <http://www.planalto.gov.br/ccivil_03/constituicao/ constituicaocompilado.htm>. Acesso em: 30 out. 2010.

BRASIL. Ministério da Educação. Lei n. 9.394 de 20 de dezembro de 1996. Estabelece as diretrizes e bases da educação nacional. Disponível em <www.planalto.gov.br/ccivil_03/leis/L9394. htm>. Acesso em: 03 out. 2009.

BRASIL. Ministério da Educação. Lei 13.005, de 25 de junho de 2014. Aprova o Plano Nacional de Educação - PNE e dá outras providências. Disponível em: <http://www.planalto.gov.br/ ccivil_03/_Ato2011-2014/2014/Lei/L13005.htm>. Acesso em: 15 de jun. 2015.

DIAS SOBRINHO, J. Avaliação: políticas educacionais e reformas da educação superior. São Paulo: Cortez, 2003.

FREITAS, L. C. Os reformadores empresariais da educação: da desmoralização do magistério à destruição do sistema público de educação. Educação \& Sociedade. Campinas, v. 33, n. 119 , p. 379-404, abr./jun. 2012.

GENTILI, P. (Org.). Pedagogia da exclusão, crítica ao neoliberalismo em educação. Petrópolis, Rio de Janeiro: Vozes, 2005.

LAVAL, C. A escola não é uma empresa: o neoliberalismo em ataque ao ensino público. Londrina: Planta, 2004.

LIMA, L. Elementos da hiperburocratização da administração educacional. In: LUCENA,C.; SILVA JR. J. dos R. (Orgs.). Trabalho e Educação no século XXI: experiências internacional. São Paulo: Xamã, 2012, p. 129-158.

MELLO, M. P de. FALLEIROS, I. Reforma da aparelhagemestatal: novas estratégias de legitimação social. In: NEVES, L. M. W. A nova Pedagogia da hegemonia: estratégia do capital para educar o consenso. São Paulo: Xamã, 2005, p. 175-205.

MÉSZÁROS, I. A crise estrutural do capital. São Paulo: Boitempo, 2009.

A educação para além do capital. São Paulo: Boitempo, 2005.

OLIVEIRA, D. Educação básica: gestão do trabalho e da pobreza. Petrópolis: Vozes, 2000.

PEREIRA, L. C. A Reforma do Estado dos anos 90: lógica e mecanismos de controle. Cadernos MARE. Brasília, 1997, v. 1. Disponível em: <http://www.planejamento.gov.br/secretarias/ upload/Arquivos/publicacao/seges/PUB_Seges_Mare_caderno01.PDF >. Acesso em: 08 abr. 2012.

RAMOS, G. P.; FERNANDES, M. C. Lutas, contradições e conflitos: a construção histórica dos Conselhos Escolares no Brasil. In: LUIZ, M. C. (Org.). Conselho escolar: algumas concepções e propostas de ação. São Paulo: Xamã, 2010. Disponível em: < portal.mec.gov.br/index. php?option=com_docman\&task >. Acesso em: 14 abr. 2011.

ROSAR, M. de F. F. Administração Escolar: um problema educativo ou empresarial. 5 ed. São Paulo: autores Associados, 2012.

RUIZ, M. J. F. A democratização da escola pública no estado doParaná (1983 a 2010). Londrina: EDUEL, 2014.

SHIROMA, E. O. Implicações da Política de profissionalização sobre a gestão e o Trabalho docente. Trabalho e Educação. v. 13, n. 2, ago./dez, 2004. p. 113-125. Disponível em: <http:// www.portal.fae.ufmg.br/seer/index.php/trabedu/article/viewFile/1175/926>. Acesso em: 15 de jun. 2015. 
Maria José Ferreira Ruiz - Edwylson de Lima Marinheiro

SILVA, I. G. Democracia e participação na "reforma” do estado. São Paulo: Cortez, 2003.

TRAGTENBERG, M. Administração, poder e ideologia. 3 ed. São Paulo: UNESP, 2005.

WALLERSTEIN, I. Capitalismo histórico e civilização capitalista. Rio de Janeiro: Editora Contraponto, 2001.

\section{Nota}

${ }^{1}$ A pesquisa conta com o financiamento da Fundação Araucária, em forma de bolsa de estudos.

* Professora doutora da Universidade Estadual de Londrina, Londrina, Paraná, Brasil.

* Mestrando em Educação pela Universidade Estadual de Londrina, Londrina, Paraná, Brasil.

\section{Correspondência}

Maria José Ferreira Ruiz - Universidade Estadual de Londrina, CECA. Cidade Universitária, CEP: 80060-500 - Londrina, Paraná - Brasil.

E-mail:mjfruiz@gmail.com - edwylson@hotmail.com

Recebido em 11 de março de 2015

Aprovado em 02 de maio de 2015 